Acta Theriologica 40 (3): 237-248, 1995.

PL ISSN 0001-70051

\title{
Habitat use and species richness of bats in a patchy landscape
}

\author{
Johnny de JONG
}

\begin{abstract}
de Jong J. 1995. Habitat use and species richness of bats in a patchy landscape. Acta Theriologica 40: 237-248.

Habitat destruction and fragmentation caused by modern forestry and agriculture are some of the main problems for the long-term survival of many species. In this study, a bat community of 11 species was investigated with the objective to evaluate the impacts of patch size, distance between habitat patches and habitat quality on species number, and also to investigate the use of corridors. Habitat islands, varying in size from 0.1 to $98.7 \mathrm{ha}$, in an agriculture-dominated landscape were surveyed. Habitat use by four species: Myotis brandti (Eversmann, 1845), M. nattereri (Kuhl, 1818), Pipistrellus pipistrellus (Schreber, 1774), and Plecotus auritus (Linnaeus, 1758), was recorded in detail. In a stepwise multiple regression species number was found to be positively related to the area of deciduous woodland, but not to the area of coniferous forest or the distance to the continuous forest. Three of the four study species avoided all kinds of open habitats. Corridors were used as hunting habitats. Different hypotheses that might explain behaviour in open habitats are discussed.
\end{abstract}

Department of Wildlife Ecology, Box 7002, S-75007 Uppsala, Sweden

Key words: bats, habitat use, distribution, species richness, corridors, landscape ecology

\section{Introduction}

Agriculture and forestry have changed the landscape over a very long period. In Sweden, the change has become very obvious during recent decades and there is evidence that this has reduced the diversity of wildlife (Robertson et al. 1990). One effect of the modern form of land use is habitat fragmentation, which means that only small patches of native vegetation remain after, for example, logging. The effects of habitat fragmentation (reviewed by Saunders et al. 1991) include change in local climate (Saunders 1982, Lovejoy et al. 1986, Kapos 1989, Klein 1989, Reville et al. 1990), isolation of populations (Mader 1984), loss of preferred habitats and increased predation (Whitney and Runkle 1981, Lovejoy et al. 1986, Yahner 1988). The degree of influence depends on time since isolation (Saunders 1989), distance between patches, size, shape (Wilcove et al. 1986), occurrence of corridors (Saunders and de Rebeira 1991), etc. There are many examples of the impact of fragmentation on wildlife (Whitcomb et al. 1981, Diamond 1984, Diamond et al. 1987, Rolstad 1991) and Wilcox and Murphy (1985) argue that this 
is the most important factor contributing to the increasing loss of biological diversity.

However, there have been very few studies of the impact of habitat fragmentation on bat populations. Bats are very mobile and can easily fly several kilometers. Is this group of species at all influenced by habitat fragmentation? How do bat populations respond to area, isolation and other factors? The last question has been investigated in some island studies. Wiles et al. (1989) found a positive relationship between population size and area in the Mariana islands, but also that quantity and quality of habitats were important factors determining the size of bat populations. Baker and Genoways (1978) analysed the bat fauna of the Antillean Island and discussed invasion routes, barriers and endemism. Ahlén (1983) studied bat fauna on islands in Scandinavia. He found that area, distance and latitude significantly affected the number of species and explained $80 \%$ of the variation. In Holland, Limpens and Kapteyn (1991) investigated flight routes of bats in an agricultural area, and found that some species ("small bat species") did not cross open fields, but followed forest edges or different types of habitat corridors like paths, lanes, hedges, wooded banks, etc. Also in a tropical area of Mexico, Estrada et al. (1993) found that open pastures were less used than other habitats. They found a negative relation between species richness and isolating distance of forest fragments.

All these studies indicate that habitat fragmentation and patchiness could be important for bats also within a small area. We know that some species, eg Nyctalus noctula (Schreber, 1774) and Eptesicus nilssoni (Keyserling et Blasius, 1839) use large hunting areas and do not follow any linear landscape elements (Kronwitter 1988, de Jong 1994), but small, slowly flying species may be affected.

In this study, I investigated species composition in a patchy landscape. I also studied habitat use by four species: Pipistrellus pipistrellus (Schreber, 1774), Plecotus auritus (Linnaeus, 1758), Myotis nattereri (Kuhl, 1818), and M. brandti (Eversmann, 1845). The objective was to test: (1) Do the quality, size and isolation of patches affect the number of species in an agricultural area? (2) Is it possible to predict which species are affected? (3) Are tree corridors used by bats?

The four study species were chosen because they are the smallest species in the study area. There are also two other small species, Myotis daubentoni (Kuhl, 1819) and M. mystacinus (Kuhl, 1819), but the former species mainly hunts above water and the latter was not found at any colony in the study area. Three of the species, $M$. brandti, $P$. pipistrellus and $P$. auritus, are very common, while $M$. nattereri is rare, but known from a few colonies (Ahlén and Gerell 1990).

\section{Study area}

All habitat patches were located within 70 kilometers of Uppsala (Sweden), and most of them were located in an agricultural area with extensive arable land in the southern part of the province of Uppland, south-west and north of Uppsala. 
Habitat use of the four selected species was studied at five separate localities: (1) Marsveden $\left(59^{\circ} 50^{\prime} \mathrm{N}, 17^{\circ} 15^{\prime} \mathrm{E}\right)$, located $20 \mathrm{~km} \mathrm{~W}$ of Uppsala, a landscape dominated by coniferous forests and clear-cuttings. There was also an area with abandoned arable land with nearby small patches of deciduous woodland (Fig. 1a). At this site, mainly $M$. brandti was studied, although $P$. auritus was also seen. (2) Långtora $\left(59^{\circ} 46^{\prime} \mathrm{N}, 17^{\circ} 10^{\prime} \mathrm{E}\right)$, located $30 \mathrm{~km} \mathrm{SW}$ of Uppsala, and dominated by modern agriculture. In the northern part, there was an area with spruce and open pine forest (Fig. 1b). Only one species, $M$. brandti, was observed here. (3) Berga $\left(60^{\circ} 6^{\prime} \mathrm{N}, 17^{\circ} 31^{\prime} \mathrm{E}\right), 20 \mathrm{~km} \mathrm{~N}$ of Uppsala,
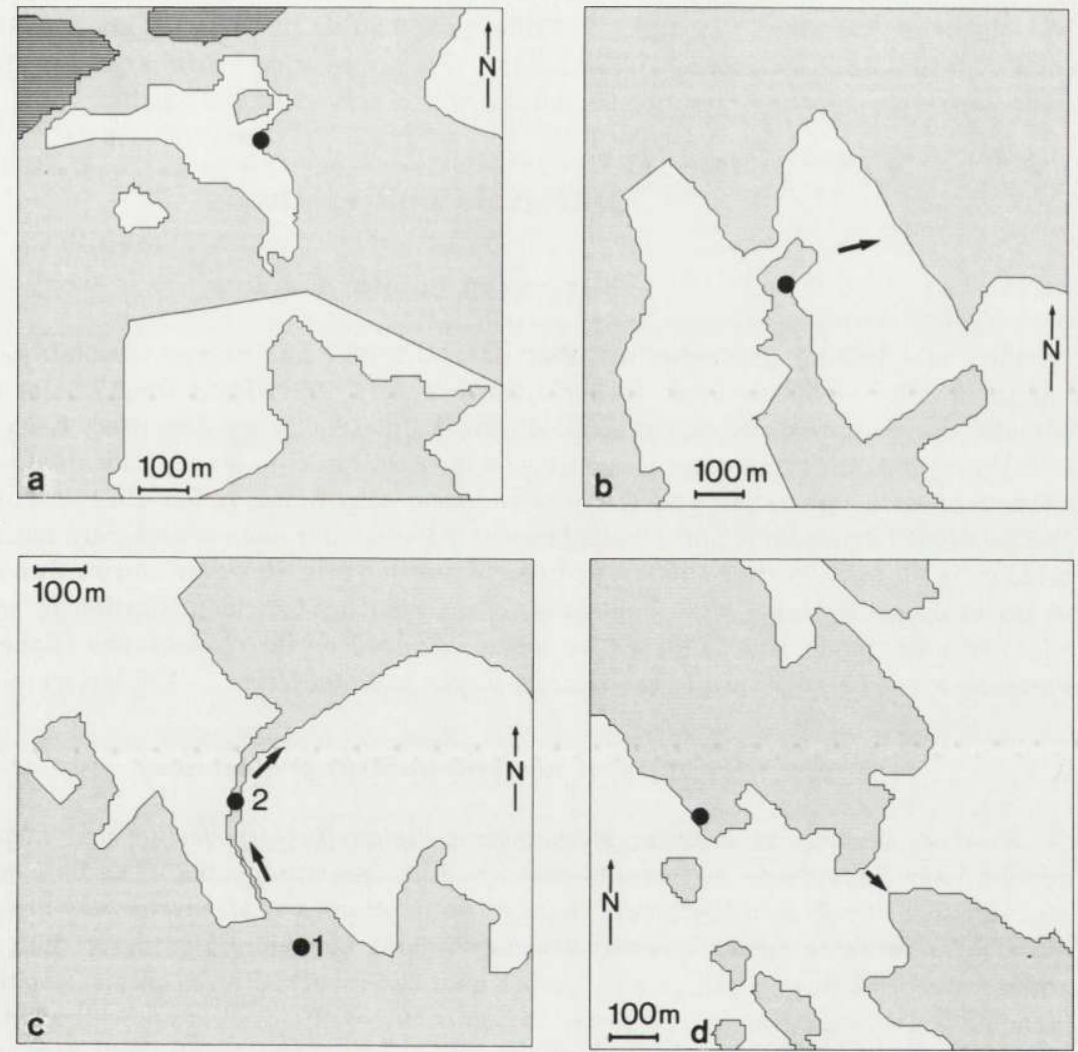

Fig. 1. Distribution of forests (grey), open areas (white) and lakes (wave pattern) as well as bat species observed in the five study areas: (a) Marsveden, Myotis brandti; (b) Långtora, Myotis brandti; (c) Berga, Myotis nattereri (1) and Plecotus auritus (2); (d) Ängsö, Pipistrellus pipistrellus; (e) Villberga, Plecotus auritus. The colonies are marked with black dots. The arrows indicate flight routes.

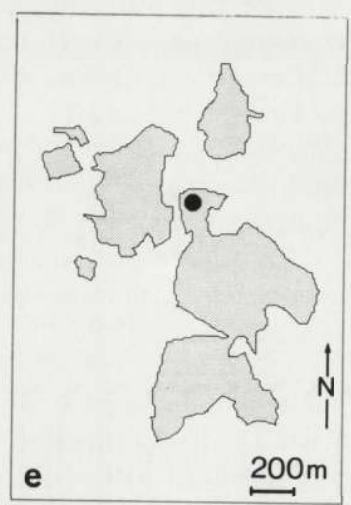


dominated by coniferous forest and clear-cuttings. In the northern part there was a big area with deciduous swamp forest, where $M$. nattereri was observed. To reach this area the bats had to cross a big clear-cutting, an open area with abandoned arable land or to follow a narrow corridor of deciduous and coniferous trees (Fig. 1c). In the middle of this corridor there was also a colony of Plecotus auritus. (4) Ängsö $\left(59^{\circ} 32^{\prime} \mathrm{N}, 16^{\circ} 54^{\prime} \mathrm{E}\right)$, an island in Lake Mälaren, $70 \mathrm{~km} \mathrm{SW}$ of Uppsala. The northern part was dominated by coniferous forest, but there were also some patches of deciduous woodland. The southern and eastern parts were dominated by fields and pastures. On the other side of these open habitats, there were both coniferous and deciduous forests (Fig. 1d). At this site, mainly P. pipistrellus was observed, but also $P$. auritus. (5) Villberga $\left(59^{\circ} 36^{\prime} \mathrm{N}, 17^{\circ} 17^{\prime} \mathrm{E}\right), 40 \mathrm{~km} \mathrm{~S}$ of Uppsala, a patch of coniferous and deciduous forest ( $74.2 \mathrm{ha}$ ) located in a vast agricultural area (Fig. 1e). There were also some parks, gardens and pastures. P. auritus was observed at this locality.

\section{Materials and methods}

\section{Surveys of habitat patches}

Fifty-nine habitat patches of different sizes (0.1-98.7 ha), degree of isolation (140-3840 m) and habitat quality were surveyed during June and July 1991. Data from earlier surveys of habitat islands, made by Ahlén et al. (unpubl.) during 1978-1986, were also used. Each island was visited 3-4 times and the mean time per visit was 30 minutes. Species identification was made by using ultrasound detectors D-980 and D-940 (Pettersson electronics; Ahlén 1981, 1990). The two sibbling species Myotis mystacinus and Myotis brandti, have similar sounds and were not separated. Another problem is the very weak sound emitted by Plecotus auritus. However, during June and the three first weeks of July the nights were light enough to permit species identification by eye. Habitat composition of each patch was analysed by using infra-red aerial photographs (Robertson et al. 1990). Patch-area and the distance to the nearest larger patch of forest ( $>100 \mathrm{ha}$ ) were measured.

\section{Habitat use and habitat preferences}

Four species, Myotis brandti, M. nattereri, Pipistrellus pipistrellus and Plecotus auritus, were studied near their roosts at five different localities (see study sites). The bats were trapped at the roost for identification in the hand. There were no colonies of $M$. mystacinus near the colonies of $M$. brandti. To estimate habitat preferences and foraging behaviour I gathered data from line-transects and a number of observation points, located near the colony at an open place or near a forest edge. I recorded flight height (to nearest meter by comparing with object of known height), whether the bats were hunting near any surface like water, tree-canopy, tree-trunk, wall etc, and flight paths (ie whether bats were crossing open areas or followed the forest-edge). The number of surveys on each transect, length of each transect and total survey time for each species was: $21,3.3 \mathrm{~km}, 32$ hours for M. brandti; $13,5.0 \mathrm{~km}, 29$ hours for $M$. nattereri; $22,2.6 \mathrm{~km}, 25$ hours for P. pipistrellus; $13,5.0 \mathrm{~km}$, 29 hours for $P$. auritus. The work at the observation points started at the same time as the bats emerged from the colony and the average time at each observation point was $30 \mathrm{~min}$ per night. The total observation time was: 11 hours for $M$. brandti; 13 hours for $M$. nattereri; 15 hours for $P$. pipistrellus; 20 hours for $P$. auritus.

Chi-square test was used for analysis of habitat preferences. In order to identify which of the habitat variables were significantly avoided or preferred the test was combined with the method used by Neu et al. (1974).

The relation between species number and different island variables (total area, area of different habitats and degree of isolation) was tested with a stepwise multiple regression analysis (SAS/SYST). When comparing flight-height and number of species in different island size classes, Kruskal-Wallis test combined with a non parametric Tukey test was used (Zar 1984). 


\section{Results}

\section{Surveys of habitat patches}

The number of species recorded in the different habitat patches varied between 0 and 8. Totally, 11 species of bats have been observed in the province of Uppland: Myotis daubentoni, M. dasycneme, $M$. nattereri, $M$. brandti, M. mystacinus, Plecotus auritus, Vespertilio murinus, Eptesicus nilssoni, Nyctalus noctula, Pipistrellus pipistrellus and P. nathusii. However, in this survey, when bats were identified by using ultrasound detectors, I did not separate between $M$. mystacinus and $M$. brandti which means that 10 species is the highest possible number.

Some of the variables (log total area, log area of deciduous forest, log area of

Table 1. Correlation matrix with $r_{\mathrm{S}}$ value and significance value. SPEC - number of species, LOGAREA - log total area, LOGDEC - log area of deciduous forest, LOGCON $\log$ area of coniferous forest, ISO - degree of isolation from mainland. $n=59$.

\begin{tabular}{lrrrrr}
\hline & SPEC & LOGAREA & LOGDEC & LOGCON & \multicolumn{1}{c}{ ISO } \\
\hline SPEC & 1.000 & 0.633 & 0.705 & 0.370 & -0.088 \\
\multirow{2}{*}{ LOGAREA } & 0.000 & $<0.001$ & $<0.001$ & 0.004 & 0.511 \\
& 0.633 & 1.00 & 0.873 & 0.754 & -0.008 \\
LOGDEC & $<0.001$ & 0.000 & $<0.001$ & $<0.001$ & 0.952 \\
& 0.705 & 0.873 & 1.000 & 0.432 & 0.090 \\
LOGCON & $<0.001$ & $<0.001$ & 0.000 & $<0.001$ & 0.499 \\
& 0.370 & 0.754 & 0.432 & 1.000 & 0.064 \\
ISO & 0.004 & $<0.001$ & $<0.001$ & 0.000 & 0.631 \\
& -0.088 & -0.008 & 0.090 & 0.064 & 1.000 \\
& 0.511 & 0.952 & 0.499 & 0.631 & 0.000 \\
\hline
\end{tabular}

coniferous forest, degree of isolation) were correlated to each other (Table 1). In a stepwise multiple regression, the best choise was the area of deciduous forest, while the other variables did not significantly contribute to the regressin $\left(r^{2}=0.50\right.$, $n=59, p<0.001$, Fig. 2).

If patches are split into four size classes: $0.1-10.0,10.1-20.0,20.1-30.0,>30.1$ $\mathrm{ha}$, it is evident that species number increases significantly in patches larger than 20 ha (Kruskal-Wallis and Tukey test, $p<0.001$, Fig. 3). Of all patches smaller than 20 ha $(n=47), M$. mystacinus /brandti was found on $8 \%, M$. nattereri on $2 \%$, $P$. pipistrellus on $19 \%$ and $P$. auritus on $0 \%$. Of all patches where only one species was recorded $(n=25)$, the most frequent species was $E$. nilssoni $(60 \%)$ followed by $P$. pipistrellus $(24 \%)$ and $M$. daubentoni $(16 \%)$. 

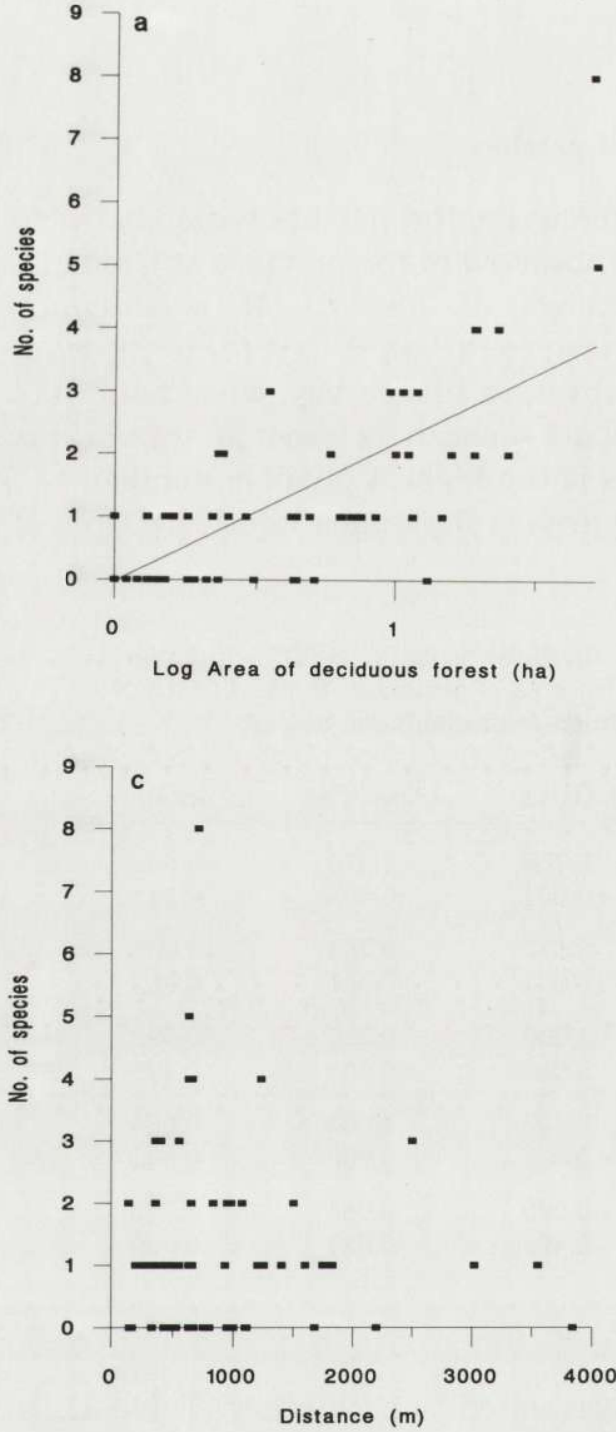

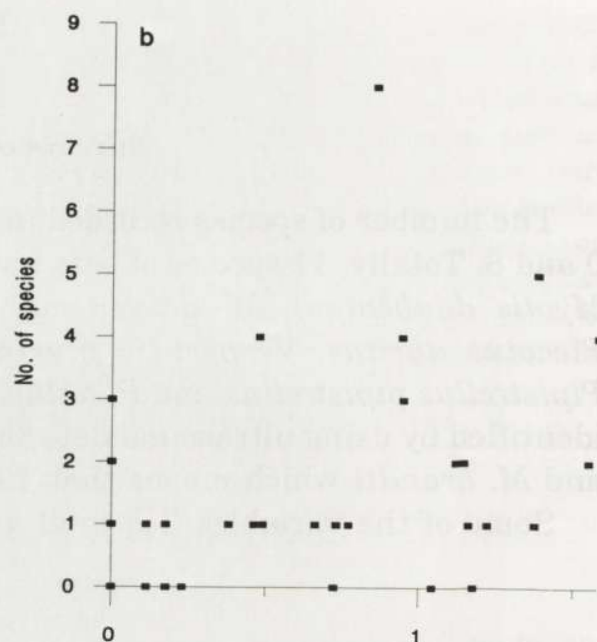

Log Area of coniferous forest (ha)

Fig. 2. The relation between species number and three different variables: (a) log area of deciduous forest, (b) log area of coniferous forest, (c) distance to mainland. In a stepwise multiple analysis species number was related to the area of deciduous forest $\left(n=59, r^{2}=0.50, p<0.001\right)$, but not to the area of coniferous forest or to the distance to mainland.

\section{Habitat use and foraging behaviour}

Myotis brandti

The results from the line-transects suggest that $M$. brandti avoided hunting in open habitats (clear-cuttings and crop-fields), while the coniferous forest is used more than expected, and deciduous woodland is used in proportion to its area (Table 2). On 5\% of the observations, bats were flying along forest-edge close to open habitats, while $8 \%$ were crossing open habitats $(n=121)$. 
Fig. 3. Mean number of bat species in forest patches of different size. The difference between $10-20$ ha and $20-30$ is significant (Kruskal-Wallis and Tukey test, $p<0.001$ ).

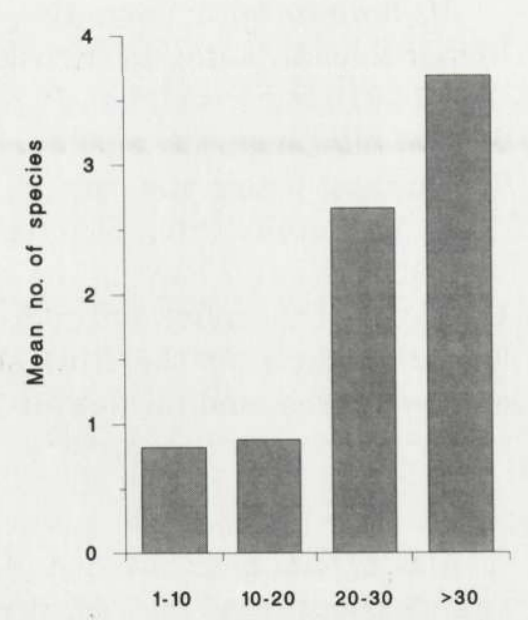

Table 2. Habitat preferences for Myotis brandti, M. nattereri and Pipistrellus pipistrellus. Chi-square test (Neu et al. 1974).

\begin{tabular}{|c|c|c|c|c|c|}
\hline Habitat & Area (ha) & Area (\%) & Observed & Expected & $p$ \\
\hline \multicolumn{6}{|l|}{ Myotis brandti } \\
\hline Arable lands & 0.92 & 16.5 & 5 & 20 & $<0.01$ \\
\hline Coniferous forest & 3.14 & 56.3 & 96 & 68 & $<0.01$ \\
\hline Deciduous forest & 0.64 & 11.5 & 9 & 14 & ns \\
\hline Clearcutting & 0.88 & 15.8 & 11 & 19 & $<0.05$ \\
\hline Total & 5.58 & 100.0 & 121 & 121 & \\
\hline \multicolumn{6}{|l|}{ M. nattereri } \\
\hline Water & 0.11 & 0.7 & 9 & 1 & $<0.01$ \\
\hline Arable land & 5.16 & 35.4 & 8 & 29 & $<0.01$ \\
\hline Garden & 2.04 & 14.0 & 4 & 12 & $<0.01$ \\
\hline Coniferous forest & 2.97 & 20.4 & 43 & 17 & $<0.01$ \\
\hline Swamp forest & 0.98 & 6.7 & 16 & 6 & $<0.01$ \\
\hline Clearcutting & 3.32 & 22.8 & 3 & 19 & $<0.01$ \\
\hline Total & 14.58 & 100.0 & 83 & 84 & \\
\hline \multicolumn{6}{|l|}{ Pipistrellus pipistrellus } \\
\hline Pasture & 0.42 & 5.3 & 21 & 12 & ns \\
\hline Arable land & 1.95 & 24.6 & 42 & 55 & ns \\
\hline Open deciduous forest & 2.79 & 35.2 & 69 & 79 & $\mathrm{~ns}$ \\
\hline Coniferous forest & 0.63 & 8.0 & 10 & 18 & $<0.05$ \\
\hline Deciduous forest & 2.13 & 26.9 & 83 & 61 & $<0.05$ \\
\hline Total & 7.92 & 100.0 & 225 & 225 & \\
\hline
\end{tabular}


$M$. brandti on average fly at $2.7 \mathrm{~m}(\mathrm{SD}=1.2, n=71)$, which is significantly higher than $M$. nattereri (Kruskal-Wallis and Tukey test, $p<0.001$ ) and P. auritus ( $p<0.001)$, but lower than P. pipistrellus $(p<0.01)$. Most of the individuals, $79 \%$, did not hunt near any surface, but $8 \%$ were observed hunting close to the ground, $7 \%$ hunting within the canopy, $4 \%$ near tree-trunks and $1 \%$ near a wall.

At one study site, Långtora, most bats crossed a small clear-cut $(180 \mathrm{~m})$ immediately after leaving the roost in the evening (marked with an arrow in Fig 1a). Some of them flew only $0.5-1 \mathrm{~m}$ above the ground, while others flew at normal height $(2-3 \mathrm{~m})$. At the other study site, Marsveden, no bats were seen crossing any open area, and all flew at $2-3 \mathrm{~m}$ above the ground.

\section{Myotis nattereri}

Also $M$. nattereri avoided all open habitats, in this case gardens, arable land and clear-cuttings. Instead, it preferred to forage within the coniferous forest or in deciduous swamp forest. It also preferred to hunt above water, but all of these observations were made within the forest, where the bats were hunting above small streams (Table 2). The forest-edge was used as foraging site in $5 \%$ of the observations, while open habitats were used in $8 \%(n=83)$.

The mean flight height was $2.2 \mathrm{~m}(\mathrm{SD}=0.9, n=52$ ). This did not differ from $P$. auritus (Kruskal-Wallis and Tukey test), but was significantly lower than $M$. brandti $(p<0.001)$ and $P$. pipistrellus $(p<0.001)$. This species forages close to a surface more frequently than the previous species: $60 \%$ did not hunt near any substrate, $15 \%$ were hunting close to the ground, $8 \%$ were hunting within the foliage, $3 \%$ were hunting near a tree-trunk, $5 \%$ were hunting near a wall and $8 \%$ were hunting above the water surface.

The tree corridors between the colony forest and the swamp forest were intensively used. Of 85 observations (made from the observation points near the colony) $99 \%$ were bats hunting in the corridor, while $1 \%$ crossed the arable field.

\section{Pipistrellus pipistrellus}

In contrast to the others this species did not avoid open habitats (eg pastures and crop-fields), but used them in proportion to their area. Coniferous forest was avoided, while deciduous woodland was preferred (Table 2), $21 \%$ of the observations were bats hunting along the forest-edge, while $12 \%$ were hunting in open habitats $(n=225)$.

The mean flight height was $3.8 \mathrm{~m}(\mathrm{SD}=2.1, n=80$ ) and this is significantly higher than all other species (Kruskal-Wallis and Tukey test, $p<0.001$ for $M$. nattereri and $P$. auritus, but $p<0.01$ for $M$. brandti). This species rarely forages close to any substrate: $92 \%$ of the observations were animals seen flying in open spaces and $8 \%$ were hunting near the canopy of deciduous trees.

Despite not avoiding small open habitats, pipistrelles were rarely seen crossing arable land, except between two points where the traffic of bats was intense 
(marked with an arrow in Fig. 1d). During 30 min the mean number of bats passing was 30.5 , all of them crossing the field from west to east without hunting.

Plecotus auritus

The species occurred at three of the five study sites. In spite of this, the number of observations only totalled 34 . Therefore it was not possible to estimate habitat preferences.

The mean flight height was $1.5 \mathrm{~m}$ (SD $=0.7, n=17$ ), which is significantly lower than for all other species (Kruskal-Wallis and Tukey test, $p<0.001$ ) except for $M$. nattereri. Of all observations, $68 \%$ were near some type of surface, mainly close to the ground, hunting a few $\mathrm{dm}$ from the vegetation. It was seen hunting above gardens, in parks, on pastures, within deciduous woodland, dense coniferous forest and in open pine forest. However, it was never seen to cross arable land. At Villberga, one individual was hunting about $800 \mathrm{~m}$ from the colony but it was still within the habitat island where the colony was located.

\section{Discussion}

Limpens and Kapteyn (1991) suggested four hypotheses to explain why some bat species avoid open habitats: 1. limited range of sonar (small species with high frequencies also have short ranges of the sound) may force individuals to follow linear landscape elements in order to orientate, 2. and 3. tree corridors give shelter from predators and/or wind, 4 . insect abundance is higher along tree corridors. Although bats normally use a special type of sonar when hunting (which can also be used for species identification), the sonar can be varied and sounds of small species are not always weak (Ahlén 1981, Rydell 1990, 1993). Small bats sometimes cross open space (in this study all of the species did so occasionally) and there is no problem for bats to disperse to habitat patches several hundred meters away. Thus, the sonar range hypothesis does not explain why some species avoid open spaces. Hypotheses number 2.-4. are more interesting. The predator hypothesis is difficult to test. There are no predators specialized on bats in the temperate region although owls, cats and some birds of prey occasionally prey on bats, especially near their roost (Petretti 1977, Ruprecht 1979). Birds of prey may be important (Speakman 1991), but should mainly affect behaviour at sunset and sunrise. In line with the fourth hypotheses, the distribution of hunting bats is known to be affected mainly by insect abundance (de Jong and Ahlén 1991), and hedgerows, forest edges, etc, have been shown to act as barriers for insects transported by the wind (Lewis 1970).

When comparing habitat preferences, flight height and foraging behaviour, there were obvious differences between the four species studied. Two of them, $M$. brandti and $M$. nattereri, significantly avoided open habitats and were rarely seen to cross open areas. At one location (Berga) the majority of observations in an open area were along a corridor of trees, which was located between the colony 
and a deciduous swamp forest. When flying in the corridor the bats were normally foraging, also in the narrowest part. All species of Myotis were rare on isolated habitat islands that were smaller than 20 ha (except $M$. daubentoni, if the patch was located near water). The data on $P$. auritus are few, but the fact that the species was rarely seen in open habitats in spite of many hours of observations near the colony, indicates that it avoids open habitats. It was never found on forest islands smaller than 20 ha. P. pipistrellus did not avoid any open habitats. It was also more common on small habitat islands and was sometimes the only species on the island. However, at Ängsö it frequently crossed open fields at the narrowest part, which indicate that large open areas of arable land is avoided. Fewer individuals than expected used arable land, while more individuals than expected hunted above pastures. These observations on habitat preferences and occurrence on habitat patches seem to be related to foraging behaviour: P. auritus is a low-flying species specialized on foraging near surfaces and within canopies. $P$. pipistrellus forages relatively high and is less specialized, and the Myotis species are intermediate. By using data on weight and wing morphology, flight speed and manoeuvrability can be predicted, and thus also habitat preferences (Baagoe 1987, Norberg 1990). Species with low wing-loading and low aspect-ratio, ie specialized on high manoeuvrability, should be most affected by habitat fragmentation. These species will not survive in areas of modern forestry or agriculture if only small, isolated patches of forest are left.

The island biogeography theory (MacArthur and Wilson 1967) predicts a correlation between species number and island size and isolation. The area and species number relationship has also been found for many organisms, including bats (Ahlén 1983). However, my result should not be compared with these theories. This study shows the importance of area size only during the period of pregnancy and lactation. In view of dispersal or migration capabilities, the bats on the habitat islands are not really isolated. The distance between small islands $(<10 \mathrm{ha})$ and big forests (>100 ha) varied between $140 \mathrm{~m}$ and $3840 \mathrm{~m}$.

To summarize this study shows that some species of bats avoid open habitats for foraging, and these species may be negatively affected by patchiness or habitat fragmentation. Small habitat islands are used by few bats species. Species number on the islands is affected by habitat types, and area of deciduous woodland is the main variable affecting the number of species. At this scale species number and degree of isolation are not related. Instead there may be a threshold value. Small habitat islands are rarely used even if the distance to the mainland is short. The negative and positive roles of corridors have been intensively debated (Soulé and Simberloff 1986, Noss 1987, Simberloff and Cox 1987). For some bat species, corridors are obviously valuable, mainly as hunting habitats, but also to connect bigger areas of forest to each other.

Acknowledgements: I thank M. Ekman and J. Gertz for their help in the field work. I am also grateful to I. Ahlén, O. Kindvall, A. Carlson and T. Pärt for comments on the manuscript. This study was a part of a project on bat ecology supported by the Swedish Council for Forestry and Agricultural Research. 


\section{References}

Ahlén I. 1981. Identification of Scandinavian bats by their sounds. Swedish University of Agricultural Sciences Report 6: 1-56.

Ahlén I. 1983. The bat fauna of some isolated island in Scandinavia. Oikos 41: 352-358.

Ahlén I. 1990. Identification of bats in flight. Swedish Society for Conservation of Nature, Stockholm: $1-50$.

Ahlén I. and Gerell R. 1990. Distribution and status of bats in Sweden. [In: European bat research 1987. V. Hanák, I. Horacek and J. Gaisler, eds]. Charles University Press, Prague: 319-325.

Baagoe H. J. 1987. The Scandinavian bat fauna: adaptive wing morphology and free flight in the field. [In: Recent advances in the study of bats. M. B. Fenton, P. Racey and J. M. V. Rayner, eds]. Cambridge University Press, Cambridge: 57-74.

Baker R. J. and Genoways H. H. 1978. Zoogeography of Antillean bats. Philadelphia Academy of Natural Sciences Special Publication 13: 53-98.

Diamond J. M. 1984. "Normal" extinctions of isolated populations. [In: Extinctions. M. H. Nitecki, ed]. University of Chicago Press, Chicago.

Diamond J. M., Bishop K. D. and Van Balen S. 1987. Bird survival in an isolated Javan woodland: Island or mirror? Conservation Biology 1: 132-142.

Estrada A., Coates-Estrada R. and Meritt D. Jr 1993. Bat species richness and abundance in tropical rain forest fragments and in agricultural habitats at Los Tuxtlas, Mexico. Ecography 16: 309-318.

Jong J., de and Ahlén I. 1991. Factors affecting the distribution pattern of bats in Uppland, central Sweden. Holarctic Ecology 14: 92-96.

Jong J., de 1994. Habitat use, home-range and activity pattern of the northern bat, Eptesicus nilssoni, in a hemiboreal coniferous forest. Mammalia 58: 535-548.

Kapos V. 1989. Effects of isolation on the water status of forest patches in the Brazilian Amazon. Journal of Tropical Ecology 5: 173-185.

Klein B. C. 1989. Effects of forest fragmentation on dung and carrion beetle communities in Central Amazonia. Ecology 70: 1715-1725.

Kronwitter F. 1988. Population structure, habitat use and activity patterns of the noctule bat, Nyctalus noctula Schreb., 1774 (Chiroptera: Vespertilionidae) revealed by radio-tracking. Myotis 26: 23-85.

Lewis T. 1970. Patterns of distribution of insects near a windbreak of tall trees. Annales of Applied Biology 65: 213-220.

Limpens H. J. G. A. and Kapteyn K. 1991. Bats, their behaviour and linear landscape elements. Myotis 29: 39-48.

Lovejoy T. E., Bierregaard R. O., Jr, Rylands A. B., Malcolm J. R., Quintela C. E., Harper L. H., Brown K. S., Jr, Powell A. H., Powell G. V. N., Schubart H. O. R. and Hays M. B. 1986. Edge and other effects of isolation on Amazon forest fragments. [In: Conservation biology. M. E. Soulé, ed]. Sinauer, Sunderland: 257-285.

MacArthur R. H. and Wilson E. O. 1967. The theory of island biogeography. Monographs in population biology. No. 1. Princeton University Press, Princeton: 1-203.

Mader H.-J. 1984. Animal habitat isolation by roads and agricultural fields. Biological Conservation 29: 81-96.

Neu C. W., Byers C. R. and Peek J. M. 1974. A technique for analysis of utilization-availability data. Journal of Wildlife Management 38: 541-545.

Norberg U. M. 1990. Vertebrate flight. Springer-Verlag, Berlin: 1-291.

Noss R. F. 1987. Corridors in real landscapes: A reply to Simberloff and Cox. Conservation Biology 1: 159-164.

Petretti F. 1977. Seasonal food habits of the barn owl (Tyto alba) in an area of central Italy. Le Gerfaut 67: 225-233 
Reville B. J., Tranter J. D. and Yorkston H. D. 1990. Impact of forest clearing on the endangered seabird, Sula abbotti. Biological Conservation 51: 23-38.

Robertson J. G. M., Eknert B. and Ihse M. 1990. Habitat analysis from infra-red aerial photographs and the conservation of birds in Swedish agricultural landscapes. Ambio 19: 195-203.

Rolstad J. 1991. Consequences of forest fragmentation for the dynamics of bird populations: conceptual issues and the evidence. Biological Journal of the Linnean Society 42: 149-163.

Ruprecht A. L. 1979. Bats (Chiroptera) as constituents of the food of barn owls Tyto alba in Poland. Ibis 121: 489-494.

Rydell J. 1990. Behavioural variation in echolocation pulses of the northern bat, Eptesicus nilssoni. Ethology 85: 103-113.

Rydell J. 1993. Variation in the sonar of an aerial-hawking bat (Eptesicus nilssonii). Ethology 93: 275-284.

Saunders D. A. 1982. The breeding behaviour and biology of the short-billed form of the White-tailed Black Cockatoo Calyptorhynchus funereus. Ibis 124: 422-455.

Saunders D. A. 1989. Changes in the avifauna of a region, district and remnant as a result of fragmentation of native vegetation: the wheatbelt of Western Australia. A case study. Biological Conservation 54: 99-135.

Saunders D. A., Hobbs R. J. and Margules C. R. 1991. Biological consequences of ecosystem fragmentation: A review. Conservation Biology 5: 18-32.

Saunders D. A. and de Rebeira C. P. 1991. Values of corridors to avian populations in a fragmented landscape. [In: Nature conservation 2. The role of corridors. D. A. Saunders and R. J. Hobbs, eds]. Surrey Beatty and Sons, Chipping Norton, Australia: 221-240.

Simberloff D. and Cox J. 1987. Consequences and costs of conservation corridors. Conservation Biology 1: 63-71.

Soulé M. E. and Simberloff D. 1986. What do genetics and ecology tell us about the design of nature reserves? Biological Conservation 35: 19-40.

Speakman J. R. 1991. The impact of predation by birds on bat populations in the British Isles. Mammal Review 21: 123-142.

Whitcomb R. F., Robbins C. S., Lynch J. F., Whitcomb B. L., Klimkiewicz M. K. and Bystrak D. 1981. Effects on forest fragmentation on avifauna of eastern deciduous forest. [In: Forest island dynamics in man dominated landscapes. R. L. Burges and D. M. Sharp, eds]. Springer Publishing, New York: $125-205$

Whitney G. G. and Runkle J. R. 1981. Edge versus effects in the development of a beech maple forest. Oikos 37: 377-381.

Wilcove D. S., McLellan C. H. and Dobson A. P. 1986. Habitat fragmentation in the temperate zone. [In: Conservation biology, the science of scarcity and diversity. M. E. Soulé, ed]. Sinauer, Sunderland: 237-256.

Wilcox B. A. and Murphy D. D. 1985. Conservation strategy: the effects of fragmentation on extinction. American Naturalist 125: 879-887.

Wiles G. J., Lemke T. O. and Payne N. H. 1989. Population estimates of fruit bats (Pteropus mariannus) in the Mariana Island. Conservation Biology 3: 66-76.

Yahner R. H. 1988. Changes in wildlife communities near edges. Conservation Biology 2: 333-339.

Zar J. H. 1984. Biostatistical analysis. Prentice-Hall International, London: 1-718.

Received 25 November 1994, accepted 29 May 1995. 